Yi-Chung Lee, MD, PhD

Pei-Chien Tsai, PhD

Yuh-Cherng Guo, MD, MS

Cheng-Tsung Hsiao, MD

Guan-Ting Liu, PhD

Yi-Chu Liao, MD, PhD*

Bing-Wen Soong, MD, $\mathrm{PhD*}$

Correspondence to

Dr. Soong:

bwsoong@ym.edu.tw or

Dr. Liao:

ycliao5@vghtpe.gov.tw
Supplemental data at Neurology.org/ng

\section{Spinocerebellar ataxia type 36 in the Han Chinese}

\section{OPEN}

\section{ABSTRACT}

Objective: To ascertain the genetic and clinical characteristics of the GGCCTG hexanucleotide repeat expansion in the nucleolar protein 56 gene (NOP56) in patients with spinocerebellar ataxia (SCA), sporadic ataxia, or amyotrophic lateral sclerosis (ALS) in Taiwan.

Methods: We conducted clinical and molecular genetic studies of 109 probands with molecularly unassigned SCA from 512 SCA pedigrees, 323 healthy controls, 502 patients with sporadic ataxia syndromes, and 144 patients with ALS. Repeat-primed PCR assays and PCR-fragment analysis for the number of short hexanucleotide repeats ( $<40$ units) were performed to ascertain NOP56 hexanucleotide repeat expansion. Genotyping included 8 microsatellite markers and 17 single nucleotide polymorphisms flanking NOP56 and covering a region of $1.8 \mathrm{Mb}$ to assess a possible founder effect.

Results: Eleven individuals from 3 SCA pedigrees have the NOP56 repeat expansions. The 3 pedigrees share a common haplotype spanning $5.3 \mathrm{~kb}$ flanking the NOP56 repeat expansions, suggesting a founder effect of spinocerebellar ataxia type 36 (SCA36) in the Han Chinese. The average age at symptom onset was $44.8 \pm 3.8$ years with truncal ataxia as the initial manifestation. Common features included slowly progressive truncal/limb ataxia, dysarthria, generalized hyperreflexia, and hearing impairment. Evidence of lower motor neuron involvement, including atrophy and fasciculation in the limb muscles and tongue, was mostly found in patients with prolonged disease duration. NOP56 repeat expansion was not detected in controls or patients with sporadic ataxic syndromes or ALS.

Conclusions: SCA36 is an uncommon subtype, which accounted for $0.6 \%(3 / 512)$ of SCA cases in the Han Chinese population. Neurol Genet 2016;2:e68; doi: 10.1212/NXG.0000000000000068

\section{GLOSSARY}

ALS = amyotrophic lateral sclerosis; ANOVA = analysis of variance; $\mathbf{C r}=$ creatinine; $\mathbf{F A B}=$ Frontal Assessment Battery; FTD = frontotemporal dementia; $\mathbf{L C L}=$ lymphoblastoid cell line; MMSE $=$ Mini-Mental State Examination; MoCA = Montreal Cognitive Assessment; MRS = magnetic resonance spectroscopy; NAA = N-acetylaspartate; $\mathbf{N C S}=$ nerve conduction studies; NOP56 = nucleolar protein 56 gene; $\mathbf{p p m}=$ parts per million; qPCR = quantitative real-time PCR; SAP = sensory action potential; SARA = Scale for the Assessment and Rating of Ataxia; SCA = spinocerebellar ataxia; $\mathbf{S C A 3 6}=$ spinocerebellar ataxia type 36; SNP = single nucleotide polymorphism; SSEP = somatosensory evoked potentials.

Spinocerebellar ataxia type 36 (SCA36), ${ }^{1,2}$ identified in 2011 as a novel subtype of SCA, is caused by the expansion of a typically large GGCCTG hexanucleotide repeat $(650-2,500)$ in the nucleolar protein 56 gene (NOP56). Unlike other CAG repeat disorders resulting in polyglutamine protein aggregation, SCA36 is an RNA-mediated neurodegenerative disorder attributable to RNA toxic gain of function. ${ }^{3}$ Other noncoding repeat expansion disorders include fragile X tremor ataxia syndrome, SCA8, SCA10, SCA31, and amyotrophic lateral sclerosis/ frontotemporal dementia (ALS/FTD) with the C9orf72 GGGGCC repeat expansion. There are few reports about SCA36; most are about populations in Japan, Spain, and France. ${ }^{1,2,4-6}$

\footnotetext{
*These authors contributed equally to the manuscript.

From the Department of Neurology (Y.-C. Lee, C.-T.H., G.-T.L., Y.-C. Liao, B.-W.S.), Taipei Veterans General Hospital, Taiwan; Department of Neurology (Y.-C. Lee, P.-C.T., Y.-C. Liao, B.-W.S.), Institute of Clinical Medicine (Y.-C.G.), and Brain Research Center (Y.-C. Lee, P.-C.T., B.-W.S.), National Yang-Ming University School of Medicine, Taipei, Taiwan; Department of Neurology (Y.-C.G.), and School of Medicine (Y.-C.G.), College of Medicine, China Medical University, Taichung, Taiwan.

Funding information and disclosures are provided at the end of the article. Go to Neurology.org/ng for full disclosure forms. The Article Processing Charge was paid by the authors.

This is an open access article distributed under the terms of the Creative Commons Attribution-NonCommercial-NoDerivatives License 4.0 (CC BY-NC-ND), which permits downloading and sharing the work provided it is properly cited. The work cannot be changed in any way or used commercially.
} 
SCA36 is a slowly progressive cerebellar ataxia similar to other late-onset ataxias, such as SCA6, SCA23, and SCA35..$^{-11}$ Although the most distinguishing feature of SCA36 is lower motor neuron involvement, discrepancies in clinical phenotypes have been reported. For example, atrophy and fasciculation of the tongue and limb muscles are present in $12 \%$ of French patients in contrast to 63\% of Japanese patients. ${ }^{5}$ As both cerebellar ataxia and lower motor neuron involvement are important features of SCA36, it would be intriguing to investigate whether the hexanucleotide repeat expansion in NOP56 is present in patients with apparently sporadic ataxia or ALS. In the present study, we aimed to identify SCA36 mutations primarily in patients with hereditary ataxias and, secondarily, in healthy controls, and individuals with sporadic ataxia syndromes and those with ALS. Furthermore, we quantified the expression of microRNA-1292 and 7 target genes to evaluate their role in SCA36 pathogenesis. ${ }^{1}$

METHODS Participants. We recruited all study participants from the Neurology Clinic of Taipei Veterans General Hospital. First, we surveyed for hexanucleotide repeat expansion in intron 1 of NOP56 in 109 molecularly unassigned index patients from 512 SCA pedigrees, after mutations responsible for SCA1, 2, 3, 6, $7,8,10,12,17,19 / 22,23,26,27,28,31$, and 35 and dentatorubral-pallidoluysian atrophy were excluded. We tentatively diagnosed SCA (i.e., inherited cerebellar ataxia, including autosomal-dominant and autosomal-recessive ataxia) according to the Harding diagnostic criteria ${ }^{12}$ and a "positive" family history, defined as the probands having at least one firstor second-degree relative with a clinical history of ataxia. We enrolled 21 individuals from the 3 SCA36 families, including 7 affected patients, 4 individuals with uncertain phenotypes, 8 unaffected individuals, and 2 spouses. In addition, we studied 502 patients with sporadic ataxia syndromes (including earlyonset cerebellar ataxia and multiple system atrophy), 144 patients with ALS, and 323 healthy controls. We diagnosed ALS according to the revised El Escorial World Federation of Neurology criteria. $^{13}$ All participants were of Han Chinese descent. All participants gave written informed consent before participating in the study. The Institutional Review Board of the Taipei Veterans General Hospital approved the study protocol (TPVGH IRB 2014-03-006A).

Clinical investigations. We defined age at onset as the age at which the earliest symptoms occurred according to statements given by patients or their caregivers and scored clinical severity of ataxia using the 40-point ( 0 being normal) validated Scale for the Assessment and Rating of Ataxia (SARA). ${ }^{14,15}$ Study participants underwent brain MRI and magnetic resonance spectroscopy (MRS) in a 1.5-T system (Signa EXCITE, GE Medical Systems, Milwaukee, WI). For MRS, we calculated peak areas for $\mathrm{N}$-acetylaspartate (NAA) at 2.02 parts per million (ppm), creatinine $(\mathrm{Cr})$ at $3.03 \mathrm{ppm}$, and the metabolite intensity ratio (NAA/Cr ratio) of both cerebellar hemispheres and vermis using FuncTool software (GE Healthcare, Milwaukee, WI). ${ }^{16,17}$ We also conducted nerve conduction studies (NCS) and EMG and pure tone audiometry ${ }^{18}$ of air conduction hearing thresholds at 4 frequencies $(500,1,000,2,000$, and $4,000 \mathrm{~Hz}$ ) using a calibrated diagnostic audiometer and evaluated somatosensory evoked potentials (SSEPs).

We conducted a global cognitive performance assessment using the Mini-Mental State Examination ${ }^{19}$ (MMSE, score range $0-30$ ), one of the most widely used screening instruments for cortical dementia, and Montreal Cognitive Assessment ${ }^{20}$ (MoCA, score range $0-30$ ). Frontal lobe executive function was evaluated using the Frontal Assessment Battery (FAB, score range 0-18). ${ }^{21}$

Mutation screening. We isolated the genomic DNA from peripheral blood leukocytes and ascertained the presence of the GGCCTG hexanucleotide repeat expansion in NOP56 using repeat-primed PCR as described previously. ${ }^{1}$ The amplicons generated by the repeatprimed PCR from an allele with an expanded repeat gave rise to a characteristic saw tooth pattern with a 6-bp periodicity on the electropherogram (figure 1A). We conducted fragment length analysis on an ABI Prism 3700 Genetic Analyzer (Applied Biosystems, Waltham, MA) to determine the repeat count in alleles with a short hexanucleotide repeat $\left(<40\right.$ units). ${ }^{5}$ Primer sequences are detailed in table e-1 at Neurology.org/ng.

Haplotype analyses. We genotyped 8 microsatellite markers and 17 single nucleotide polymorphisms (SNPs) flanking the NOP56 (GGCCTG)n repeat covering $1.8 \mathrm{Mb}$ in 21 family members from the 3 Chinese SCA36 pedigrees (tables e- 1 and e-2). We used HAPLORE software for haplotype inferences. ${ }^{22}$

Lymphoblastoid cell lines. We cultured Epstein-Barr virustransformed human lymphoblastoid cell lines (LCLs) from 5 patients with SCA36 (II-4 from pedigree A; II-1, II-3, and II-4 from pedigree $\mathrm{B}$; and II-1 from pedigree C) and 5 sex- and ethnicity-matched healthy controls following a standard protocol. ${ }^{23}$ LCLs were cultured in RPMI-1640 medium (ATCC, Manassas, VA) supplemented with $20 \%$ fetal bovine serum (Invitrogen, Carlsbad, CA) and $100 \mathrm{U} / \mathrm{mL}$ of penicillin/ streptomycin.

Quantitative real-time PCR for microRNA-1292 and target genes. We partitioned microRNA-1292 from the extracted total RNA by reverse transcription using a TaqMan microRNA reverse transcription kit (Applied Biosystems) and performed quantitative real-time PCR (qPCR) using TaqMan microRNA assays with normalization to RNA-U6B (Applied Biosystems) in an ABI7500 real-time PCR machine (Applied Biosystems).

Using TargetScan 6.2 (http://targetscan.org/), we predicted 7 genes (SRSF6, FUS, SPG7, ITPKA, GRIK3, GRIN2B, and $G A D 2$ ) to be target genes of microRNA-1292 (table e-3). Relative expression of each target gene was determined in LCLs using qPCR with specific primers (table e-1). We calculated expression ratios as the normalized threshold cycle $(\mathrm{Ct})$ value difference with the adjustment for the amplification efficiency relative to glyceraldehyde-3-phosphate dehydrogenase.

Statistical analyses. For cellular studies, we present variables as mean \pm SEM from 3 independent experiments. The Student $t$ test compares the expression of microRNA-1292 and its target genes between controls and patients with SCA36. Analysis of variance (ANOVA) compares the hexanucleotide repeat counts of NOP56 in the controls, patients with sporadic ataxic syndromes, and those with ALS. A 2 -sided $p$ value $<0.05$ is considered significant. 
Figure 1 Detection of NOP56 hexanucleotide repeat expansions
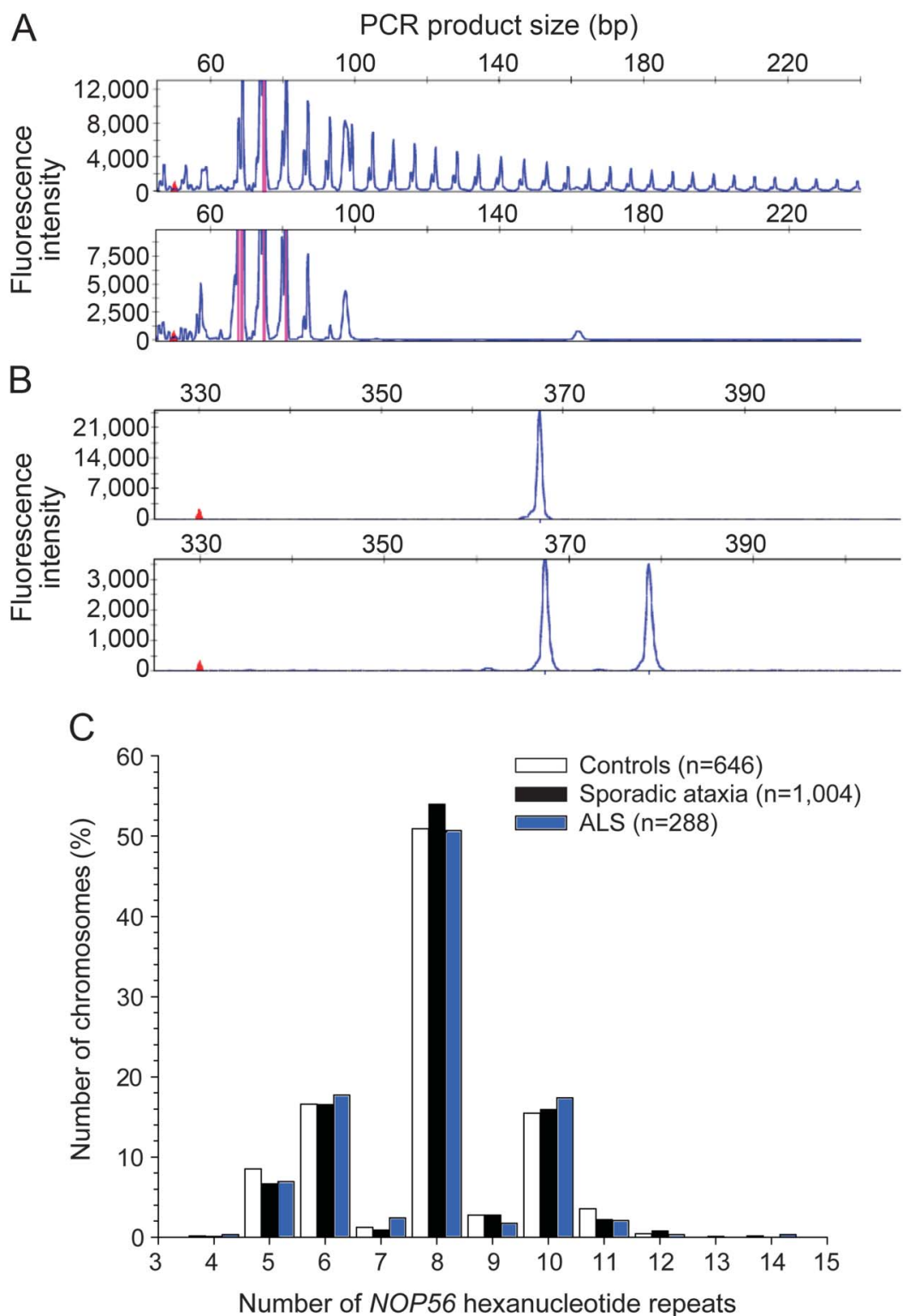

(A) Attenuating peaks of nucleolar protein 56 gene (NOP56) (GGCCTG)n expansions by repeat-primed PCR in a patient with SCA36 (upper panel) and normal features in a healthy control (lower panel); (B) Fragment length analysis: a single peak indicates either the presence of 2 homozygous alleles of short hexanucleotide repeats or 1 short hexanucleotide repeat and a large repeat expansion (>650 repeats) that failed to be amplified (upper panel), whereas 2 different peaks indicate the presence of 2 normal heterozygous alleles (lower panel). (C) Hexanucleotide repeat counts in healthy controls, patients with sporadic ataxic syndromes, and those with ALS in this study. ALS = amyotrophic lateral sclerosis.

RESULTS Identification of hexanucleotide repeat expansion in NOP56. We identified hexanucleotide repeat expansion in NOP56 in 3 index cases from the 109 probands with molecularly unassigned SCA among the 512 pedigrees (figure 1A). Therefore, SCA36 accounted for $0.6 \%(3 / 512)$ of SCA in the Han Chinese in this study.

Because short hexanucleotide repeat expansion (15-40 units) has been recently described in a few patients with SCA $36,{ }^{5}$ we conducted fragment length analysis to determine the repeat length of alleles with short NOP56 hexanucleotide repeat expansions (figure 1B). We did not observe NOP56 (GGCCTG)n expansion in the 323 controls, 502 patients with sporadic ataxia syndromes, or 144 patients with ALS. None carried a NOP56 (GGCCTG)n repeat with a size exceeding the threshold of 14 units (figure 1C). There was no difference in the distribution of the NOP56 hexanucleotide repeat lengths among healthy controls, patients with sporadic ataxia syndromes, and those with ALS $(7.86 \pm 1.61,7.91 \pm 1.52$, and $7.88 \pm 1.58$, respectively, ANOVA $p=0.81$ ).

Clinical characteristics. Repeat-primed PCR resulted in the identification of expanded NOP56 GGCCTG hexanucleotide repeats in 11 individuals from 3 pedigrees with an autosomal-dominant ataxic syndrome (figure 2). We clinically evaluated 5 of the 7 patients with ataxic symptoms; the average age at onset was $44.8 \pm 3.8$ years (mean $\pm \mathrm{SD}$; range 43-50; table 1). The phenotypes of 4 other individuals with expanded GGCCTG repeats in NOP56 were not accessible (II-7, III-1, and III-3 from pedigree $A$ and III-1 from pedigree B).

The index case of pedigree A (II-4) initially presented with dizziness, clumsy hands, and progressive gait unsteadiness at the age of 47 years. He also experienced dysarthria, tendency to choking, and diplopia as the disease advanced, along with hearing impairment, muscle atrophy in the thighs, and leg muscle cramps. On examination at age 63 , the patient had saccadic pursuits, ataxic dysarthria, limb dysmetria, generalized hyperreflexia, brisk jaw jerk, glabellar reflex, and Babinski signs. He was barely able to stand without assistance. Limb ataxia remained mild with preserved handwriting. The patient also had atrophy and fasciculation in the tongue, quadriceps, and hamstrings and impaired vibration sense in the toes. He had no bradykinesia, hand tremor, or other parkinsonism features and had preserved pinprick, light touch, and proprioception. He had EMG features of reduced recruitment and the presence of giant motor unit potentials. Over a 10 -year period, the patient's amplitudes of sensory action potentials (SAPs) of the sural nerves gradually decreased (10.4 and 12.4 $\mu \mathrm{V}$ at age 53 ; 6.2 and $6.3 \mu \mathrm{V}$ at age 63 ), suggesting progressive mild-to-moderate sensory polyneuropathy. Progressive hearing impairment began at age 60 , with an average hearing threshold of $40 \mathrm{db}$ in the left ear and $32.5 \mathrm{db}$ in the right ear at age 63. His SARA score was 21 fifteen years after disease onset and 2 points worse 1 year later. The patient had normal cognitive function with an MMSE score of 28 but mildly impaired frontal executive function $($ FAB score $=12)$. Brain MRI revealed diffuse cerebellar atrophy and mild atrophy of the cerebral cortices (figure 3, A and B). MRS 16 years after onset 
Pedigree A

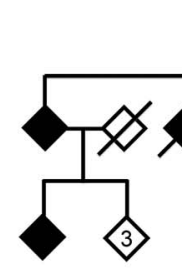

$\not D$

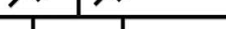

$1-1$
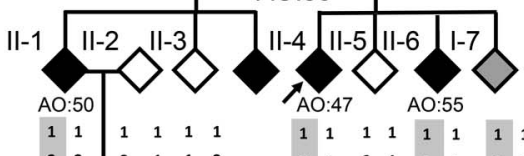

$\begin{array}{llllll}2 & 3 & 2 & 1 & 1 & 3\end{array}$

$\begin{array}{llllll}3 & 2 & 3 & 3 & 3 & 2\end{array}$

\begin{tabular}{ll|llll}
$G$ & $G$ & $G$ & $A$ & $G$ & $G$
\end{tabular}

A $G$ G

$\begin{array}{llllll}T & C & C & C & C & C\end{array}$

$\begin{array}{llllll}C & C & C & T & C & C\end{array}$

T A

\begin{tabular}{lllllll}
\hline G & A & G & G & G & A \\
\hline & T & T & T & T & T
\end{tabular}

$\begin{array}{llllll}T & T & T & T & T & T\end{array}$

$\begin{array}{llllll}R & 8 & 10 & 8 & 8 & 8\end{array}$

$\begin{array}{llllll}\text { C } & \text { A } & \text { C } & \text { C } & \text { C } & \text { A }\end{array}$

$\begin{array}{llllll} & \text { l } & \text { l } & \text { l } & \text { I } & \text { I }\end{array}$

$\begin{array}{llllll}T & C & T & T & T & C\end{array}$

\begin{tabular}{ll|llll}
3 & 2 & 3 & 4 & 5 & 2
\end{tabular}

\begin{tabular}{llllll}
\hline & $T$ & $C$ & $C$ & $C$ & $T$
\end{tabular}

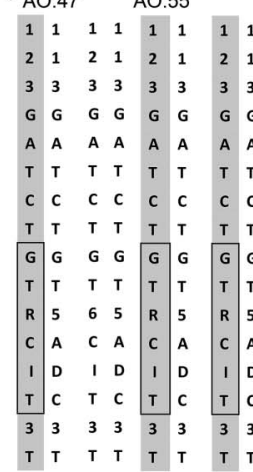

III-1 III-2 III-3 III-4

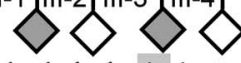

\begin{tabular}{|ll|}
\hline Marker & Position \\
\hline D20S906 & 1524930 \\
\hline D20S179 & 1996718 \\
\hline D20S113 & 2054914 \\
\hline rs1015159 & 2612360 \\
\hline rs7509377 & 2627355 \\
\hline rs6083911 & 2636989 \\
\hline rs2038246 & 2646724 \\
\hline rs6083954 & 2652330 \\
\hline rs2073196 & 2652410 \\
\hline rs6083956 & 2652468 \\
\hline NOP56 & 2652753 \\
\hline rs6050911 & 2653521 \\
\hline rs60145378 & 2653641 \\
\hline rs6753 & 2657933 \\
\hline D20S198 & 2661047 \\
\hline rs2422824 & 2666724 \\
\hline
\end{tabular}

$\begin{array}{llllllll}1 & 1 & 1 & 1 & 1 & 1 & 1\end{array}$

$\begin{array}{llllllll}3 & 2 & 3 & 1 & 2 & 1 & 3 & 2\end{array}$

$\begin{array}{lllllllll}2 & 3 & 2 & 3 & 3 & 3 & 2 & 3\end{array}$

G G G A $G$ A $A$ G

$\begin{array}{llllllllllllllllllllllllll}A & G & G & G & A & G & G & G\end{array}$

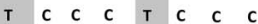

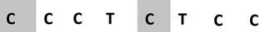

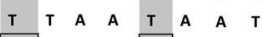

\begin{tabular}{lllllllllllll}
\hline & $G$ & $A$ & $G$ & $G$ & $G$ & $A$ & $G$
\end{tabular}

\begin{tabular}{llll|lllll}
\hline & $T$ & $\mathbf{T}$ & $\mathrm{T}$ & $\mathbf{T}$ & $\mathbf{T}$ & $\mathbf{T}$ & $\mathbf{T}$
\end{tabular}

\begin{tabular}{llll|lllll}
$R$ & 10 & 8 & 8 & R & 8 & 8 & 10
\end{tabular}

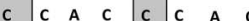

\begin{tabular}{llll|l|lll}
1 & 1 & 1 & 1 & 1 & 1 & 1 & 1
\end{tabular}

\begin{tabular}{lllll|lllll}
$T$ & $T$ & $C$ & $T$ & $T$ & $T$ & $C$ & $T$
\end{tabular}

$\begin{array}{llllllll}3 & 3 & 2 & 4 & 3 & 4 & 2 & 3\end{array}$

$\begin{array}{llllllllllllll} & T & C & T & C & T & C & T & C\end{array}$

digree

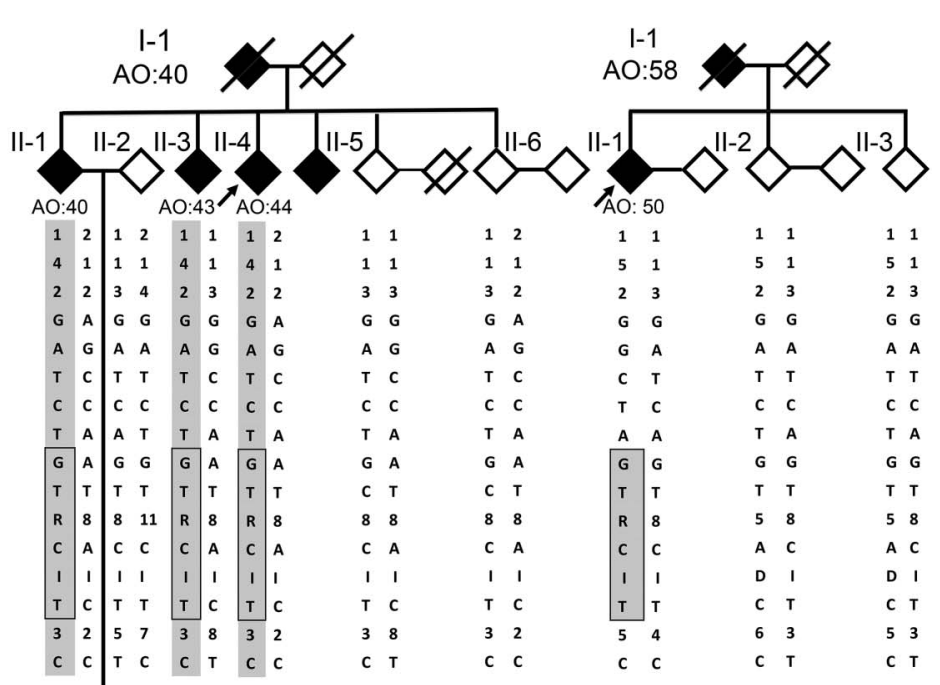

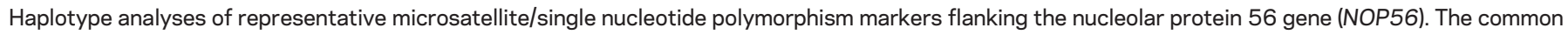

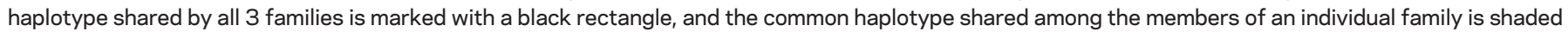

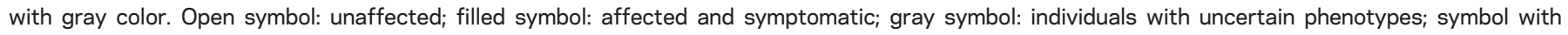
a diagonal line: deceased; arrow: proband. I = insertion; D = deletion.

featured an impaired biochemical profile in the cerebellar hemispheres and vermis with an NAA/Cr ratio of 0.77 and 0.74 in comparison with $1.0 \pm 0.13$ and $0.9 \pm 0.11$ in healthy controls. ${ }^{16,17}$

Patient II-4 of pedigree B showed progressive gait difficulties and slurred speech and choked easily since age 44 . On examination at age 52, he had impaired ocular pursuits, increased muscle tone, generalized hyperreflexia, and lower limb muscle atrophy. His NCS and SSEPs were within normal ranges. The patient's family history was remarkable for 1 elder brother, 1 elder sister, and 1 younger sister with similar ataxic symptoms (figure 2, table 1). The common features of patients with ataxic symptoms (II-1, II-3, and II-4) in this pedigree included truncal ataxia, saccadic pursuits, ataxic dysarthria, dysphagia, hearing impairment, increased muscle tone, and generalized hyperreflexia.
Leg muscle cramps were a frequent complaint. We did not observe tongue atrophy or fasciculation or cognitive dysfunction on examination.

The clinical course and manifestations of patient II-1 from pedigree $C$ resembled the affected patients from pedigrees A and B (table 1). This patient's initial clinical features were progressively unsteady gait and a propensity to fall, since age 50 years. Seven years after disease onset, she was unable to stand or walk in tandem and had subtly impaired hand coordination. The patient had fragmented pursuits, mild dysarthria, postural hand tremors, generalized hyperreflexia, and absent Babinski sign. We did not observe tongue or limb atrophy or fasciculation. The patient reported subtle impairment of vibration sense on the toes with mild sensory neuropathy on NCS (sural SAPs $=11.8$ and $9.8 \mu \mathrm{V}$ at age 57). Tinnitus and subjective 
Table 1 Clinical characteristics of patients with spinocerebellar ataxia type 36 in the literature and from the present study

\begin{tabular}{|c|c|c|c|c|c|c|c|c|c|c|}
\hline & \multicolumn{6}{|l|}{ Present study } & \multirow{3}{*}{$\frac{\text { Ref } 1}{\text { Western Japan }}$} & \multirow{3}{*}{$\frac{\text { Ref } 2}{\text { Spain }}$} & \multirow{2}{*}{\multicolumn{2}{|c|}{ Ref 5}} \\
\hline & \multirow[b]{2}{*}{$\begin{array}{l}\text { Family A } \\
\text { II-4 }\end{array}$} & \multicolumn{3}{|c|}{ Family B } & \multirow[b]{2}{*}{$\begin{array}{l}\text { Family C } \\
\text { II-1 }\end{array}$} & \multirow[b]{2}{*}{$\begin{array}{l}\text { Overall } \\
\text { Han Chinese }\end{array}$} & & & & \\
\hline & & II-1 & II-3 & II-4 & & & & & France & Eastern Japan \\
\hline Sex & M & M & $\mathrm{F}$ & M & $\mathrm{F}$ & $3 \mathrm{M} / 2 \mathrm{~F}$ & $8 \mathrm{M} / 6 \mathrm{~F}$ & $20 \mathrm{M} / 24 \mathrm{~F}$ & $8 \mathrm{M} / 12 \mathrm{~F}$ & $4 \mathrm{M} / 4 \mathrm{~F}$ \\
\hline Age at onset, y & 47 & 40 & 43 & 44 & 50 & $44.8 \pm 3.8$ & $53.1 \pm 3.5$ & $52.8 \pm 7.4$ & $50.0 \pm 6.9$ & $52.3 \pm 8.6$ \\
\hline Age at examination, $y$ & 63 & 52 & 55 & 52 & 57 & $55.8 \pm 4.5$ & $67.1 \pm 8.5$ & $63.8 \pm 12.5$ & $61.3 \pm 10.0$ & $61.0 \pm 8.3$ \\
\hline Truncal ataxia & +++ & ++ & ++ & ++ & ++ & $100 \%$ & $100 \%$ & $98 \%$ & $100 \%$ & $88 \%$ \\
\hline Limbs ataxia & ++ & + & + & + & + & $100 \%$ & $93 \%$ & $88 \%$ & NA & NA \\
\hline Saccadic pursuit & + & + & + & + & + & $100 \%$ & $93 \%$ & $64 \%$ & $39 \%$ & $63 \%$ \\
\hline Ataxic dysarthria & ++ & + & + & + & + & $100 \%$ & $100 \%$ & $88 \%$ & $61 \%$ & $100 \%$ \\
\hline Dysphagia & + & + & + & + & + & $100 \%$ & $43 \%$ & NA & NA & NA \\
\hline $\begin{array}{l}\text { Tongue atrophy and } \\
\text { fasciculation }\end{array}$ & + & - & - & - & - & $20 \%$ & $71 \%$ & $61 \%$ & $12 \%$ & $63 \%$ \\
\hline $\begin{array}{l}\text { Muscle atrophy and } \\
\text { fasciculation }\end{array}$ & ++ & + & + & + & - & $80 \%$ & $64 \%$ & NA & NA & NA \\
\hline Hyperreflexia & +++ & +++ & +++ & +++ & +++ & $100 \%$ & $79 \%$ & $41 \%$ & $67 \%$ & $63 \%$ \\
\hline Hearing impairment & ++ & ++ & ++ & ++ & - & $80 \%$ & NA & $74 \%$ & $44 \%$ & $88 \%$ \\
\hline Impaired vibration & + & - & - & - & + & $40 \%$ & $0 \%$ & NA & $39 \%$ & $75 \%$ \\
\hline $\begin{array}{l}\text { SARA score (age at } \\
\text { examination) }\end{array}$ & $\begin{array}{l}21(62) ; 23 \\
(63)\end{array}$ & NA & NA & NA & $9.5(54) ; 13.5$ (57) & $16.3 \pm 9.5$ & $20.7 \pm 7.0$ & NA & $17.8 \pm 7.3$ & $13.7 \pm 4.8$ \\
\hline Other symptoms & Muscle cramps & $\begin{array}{l}\text { Muscle } \\
\text { cramps }\end{array}$ & $\begin{array}{l}\text { Muscle cramps, } \\
\text { intention tremors }\end{array}$ & $\begin{array}{l}\text { Muscle } \\
\text { cramps }\end{array}$ & Postural tremors & & $\begin{array}{l}\text { End-gaze nystagmus } \\
(29 \%)\end{array}$ & $\begin{array}{l}\text { Tremors }(7 \%), \text { ptosis } \\
(9 \%)\end{array}$ & $\begin{array}{l}\text { Muscle cramps }(5 \%) \\
\text { postural tremors }(29 \%), \\
\text { ptosis }(12 \%)\end{array}$ & $\begin{array}{l}\text { Postural tremors } \\
(25 \%), \text { ptosis (50\%) }\end{array}$ \\
\hline
\end{tabular}

Abbreviations: $-=$ absent $+=$ mild $++=$ moderate; NA = not available; SARA = Scale for the Assessment and Rating of Ataxia. 

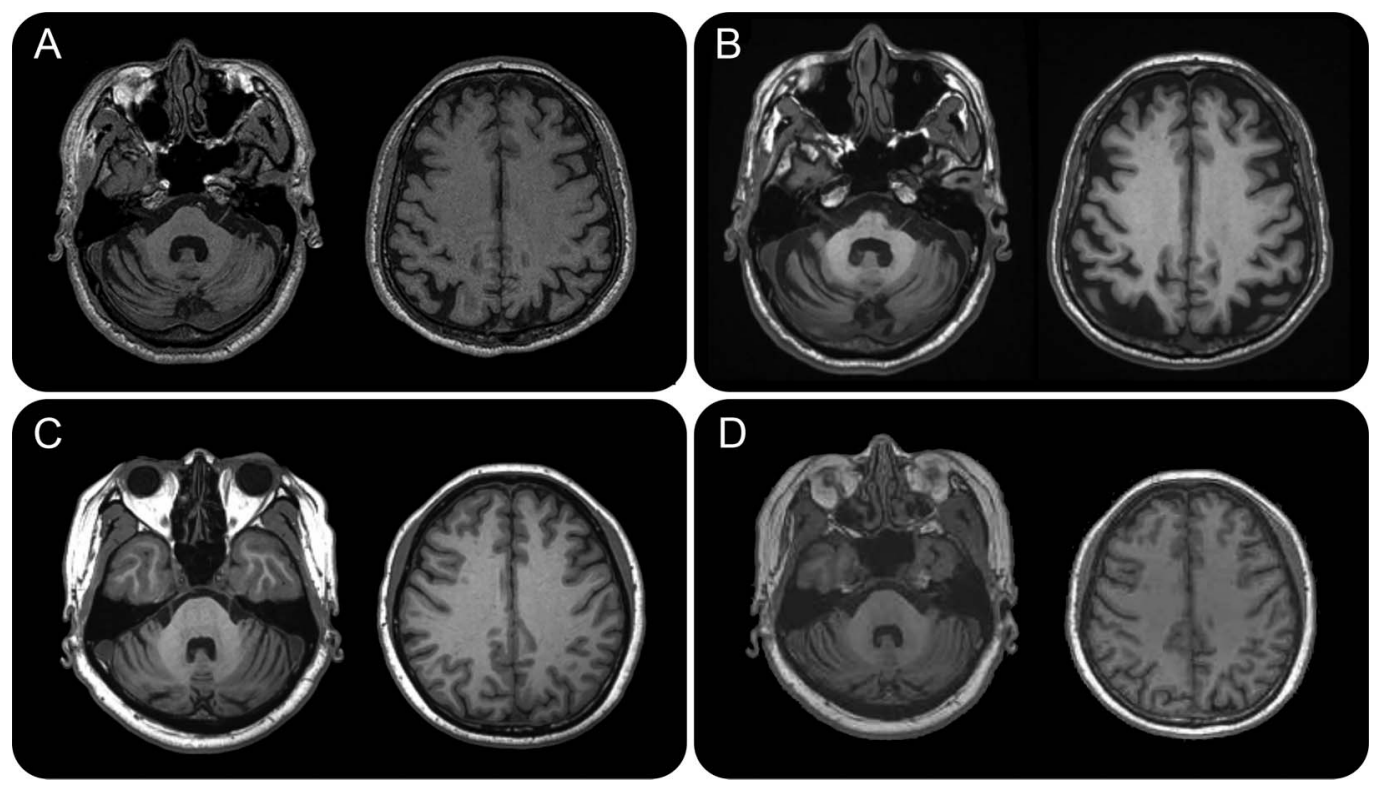

Patient II-4 in pedigree A with disease duration of 6 years (A) and 16 years (B). Patient II-1 in pedigree $C$ with disease duration of 4 years (C) and 7 years (D).

hearing impairment occurred at age 55, and she had mildly impaired hearing at age 57 (hearing threshold of $32.5 \mathrm{db}$ at $4,000 \mathrm{~Hz}$ ). This patient had a SARA score of 9.5, 4 years after disease onset and 13.5, 3 years later. Her memory and cognition (MMSE score $=30$, MoCA score $=28$ ) seemed normal, but executive function $(\mathrm{FAB}$ score $=14)$ was marginal. Brain MRI results showed diffuse cerebellar atrophy with preserved cerebral and brainstem structures (figure 3, C and D). MRS featured mildly reduced $\mathrm{NAA} / \mathrm{Cr}$ ratios in the cerebellar hemispheres and vermis (0.80 and 0.84 , respectively). The patient's father (I-1 of pedigree C) began to manifest progressive gait unsteadiness and tendency to fall at age 58 . His report showed diplopia, easy choking, muscle atrophy in the thighs, and hearing impairment toward the end of his life.

Haplotype studies. We conducted haplotype studies in 21 individuals from the 3 pedigrees, including 7 patients, 4 individuals with uncertain phenotypes, 8 unaffected individuals, and 2 spouses (figure 2). Families A and B shared a common haplotype between loci rs1015159 and D20S198, which delimited a 48-kb region flanking the (GGCCTG)n expansion. Families A, B, and C shared the same haplotype within a smaller region of $5.3 \mathrm{~kb}$ (rs2073196 to rs6753) (figure 2 and table e-2).

MicroRNA-1292 and its target genes. We observed reduced microRNA-1292 expression levels (63\%) in 5 patients with SCA36 compared with 5 healthy controls $(0.37 \pm 0.09$ vs $1.08 \pm 0.21, p=0.01$; figure e-1). In silico prediction suggested that $S R S F 6$, FUS, SPG7, ITPKA, GRIK3, GRINB2, and GAD2 were potential targets of microRNA-1292 (table e-3). Four genes (SRSFG, FUS, SPG7, and ITPKA) had unaltered expression for patients with SCA36 and healthy controls; 3 genes (GRIK3, GRINB2, and $G A D 2$ ) were not measureable in LCLs (figure e-1).

DISCUSSION After characterizing the clinical features of 5 patients with SCA36 from 3 Chinese pedigrees, our data indicate that SCA36 accounts for only a small percentage $(0.6 \%)$ of SCAs among the Han Chinese. Prevalence is much lower than that reported in Galicia, Spain (6.3\%), Okayama, Japan (3.6\%), France (1.9\%), or metropolitan Tokyo, Japan (1.5\%). . $^{1,2,4,5}$

The phenotypes of SCA36 are quite homogeneous across different ethnic groups. Common features include truncal ataxia as the initial and most prominent symptom, followed by mild appendicular ataxia, ataxic dysarthria, saccadic pursuits, and generalized hyperreflexia with or without Babinski sign (table 1). Hearing impairment is also a distinguishing feature, present in three-fourths of SCA36 patients in Taiwan, Japan, and Spain $(74 \%-88 \%)$ and less frequently in France (44\%). ${ }^{1,2,4,5}$ Hearing is remarkably impaired at high frequencies and hearing defects correlate with disease duration and SARA scores, ${ }^{24}$ suggesting a link between sensorineural hearing loss and SCA36 pathogenesis. In contrast to the much higher percentage $(61 \%-71 \%)$ noted in initial reports, we observed tongue atrophy and fasciculation in only $20 \%$ of cases in this study 
$\left(12 \%\right.$ in France $^{5}$ and $25 \%$ in Japan $^{6}$; table 1$){ }^{1,2}$ Because lower motor neuron involvement is more frequently reported in patients with a prolonged disease course, it might not be appropriate to regard such involvement as a prerequisite for clinical diagnosis of SCA36. Thorough cognitive assessment in 2 of our patients revealed mildly impaired executive function without defects in other cognitive domains. One report described a SPECT imaging study in patients with SCA36, which showed reduced cerebral blood flow in the inferior frontal, dorsolateral prefrontal, and ventral frontal cingulate gyri, ${ }^{25}$ implicating an anatomical basis for the cognitive impairment. Because a GGGGCC hexanucleotide repeat expansion in C9orf72 is an important cause of both ALS and FTD ${ }^{26}$ it would be intriguing to learn whether an NOP56 GGCCTG hexanucleotide repeat expansion also affects cognitive function by sharing similar molecular underpinnings.

The pathogenic mechanism underlying hexanucleotide repeat expansion in intron 1 of NOP56 remains to be elucidated. Abnormal expansion of short segment repeats in noncoding regions may cause RNA-mediated toxicity, including aberrant transcription at mRNA splicing and processing, sequestration of mRNAassociated protein complex, translation silencing by antisense transcripts, and repeat-associated non-ATG translation. ${ }^{3,27,28}$ Typically, these noncoding RNA expansion diseases are caused by hundreds to thousands of repeat unit expansions, as seen in myotonic dystrophy 1 (approximately mean 650 repeats for classic form), ${ }^{29,30}$ SCA10 (800-4,500 repeats), ${ }^{31,32}$ SCA31 (2.5-3.8 kb insertion), ${ }^{33,34}$ and ALS/FTD caused by the C9orf72 repeat expansion (400-4,400 repeats are unambiguously pathogenic). ${ }^{35}$ For SCA36, expanded repeat alleles ranging from approximately 650 to 2,500 repeats were considered typically pathogenic, ${ }^{1,2}$ although a recent study found that (GGCCTG)n repeats of 25-31 units might also contribute to ataxic symptoms in SCA36 pedigrees. 5 In this study, none of the 969 non-SCA individuals (controls, patients with sporadic ataxia, and those with ALS) have an NOP56 hexanucleotide repeat longer than 14 units.

The gene encoding microRNA-1292 is located 19 bp downstream of the NOP56 (GGCCTG)n repeat and, therefore, perturbed microRNA-1292 expression has been implicated in SCA36 pathogenesis. ${ }^{1}$ In agreement with the literature, we observed reduced expression of microRNA-1292 in LCLs of our SCA36 patients compared with the controls. Current data, however, were insufficient to support a regulatory role for microRNA-1292 in the predicted target genes. It is possible that microRNA-1292 expression is simply an epiphenomenon of abnormal (GGCCTG)n expansion and might not play an active role in disease pathogenesis. Three microRNA-1292 target genes (GRIK3,
GRINB2, and GAD2) were not measureable in LCLs. Arguably, LCLs may not be an appropriate platform to study SCA36 pathogenesis because such cell lines might not faithfully recapitulate the pathologic phenotypes of Purkinje cells.

Han Chinese individuals carrying the expanded SCA36 hexanucleotide repeats might have originated from the same ancestor. The 3 SCA36 pedigrees in this study shared a common haplotype spanning from loci rs2073196 to rs6753 (figure 2). It is of interest to note that the haplotype that comprised 7 SNP markers in a $1.3-\mathrm{kb}$ region flanking the NOP56 hexanucleotide repeats (rs2073196 to rs78833048) was identical among the French, Japanese, and Taiwanese patients with SCA36. ${ }^{5}$

In conclusion, SCA36 is a rare subtype of SCAs in the Han Chinese population. In patients with lateonset SCA and a protracted course, lower motor neuron signs in the limbs and tongue might suggest the possibility of SCA36. Impaired hearing and executive function might be other diagnostic clues, but this needs further verification.

\section{AUTHOR CONTRIBUTIONS}

Yi-Chung Lee: designing the study; analyses and interpretation of the data; and drafting the manuscript. Pei-Chien Tsai: conducting cellular experiments; analyses; and interpretation of the data. Yuh-Cherng Guo: patient enrollment; analyses; and interpretation of the data. ChengTsung Hsiao: patient enrollment; analyses; and interpretation of the data. Guan-Ting Liu: conducting cellular experiments. Yi-Chu Liao: analyses and interpretation of the data; conducting statistical analysis; and drafting the manuscript. Bing-Wen Soong: conceptualizing and designing the study; patient enrollment; and revising the manuscript for intellectual content.

\section{ACKNOWLEDGMENT}

The authors thank Profs. Akio Koizumi and Hatasu Kobayashi for generously providing DNA from Japanese patients with SCA36 as a positive control for NOP56 hexanucleotide repeat-primed PCR experiments.

\section{STUDY FUNDING}

The research was supported by grants from the Ministry of Science and Technology, Taiwan, ROC (NSC99-2314-B-010-013MY3, NSC-101-2325-B-010-014, NSC101-2628-B-075A-001-MY2, NSC102-2628-B-075-006-MY3, NSC103-2314-B-75-076-MY3, and MOST 103-2314-B-010-049-MY3), the Brain Research Center, National Yang-Ming University (104AC-B19), the High-Throughput Genome Analysis Core Facility and Bioinformatics Consortium of Taiwan of the National Core Facility Program for Biotechnology, Taiwan (NSC 101-2319-B-010-001), Veterans General Hospitals and University System of Taiwan Joint Research Program (VGHUST101-G7-3-1, VGHUST101-G7-3-3, VGHUST102-G7-7-1, and VGHUST102-G77-2) and Taipei Veterans General Hospital (V101C-045, V102C-124, V103C-109, V104C-061, V104C-079, V104E9-006, and V105C048), and research funds supported by the Taiwan Ataxia Association and the Hsu Tsung Pei Medical Research Fund.

\section{DISCLOSURE}

Dr. Yi-Chung Lee has received travel/speaker honoraria from the Japanese Society of Neurology; has served on the editorial board of Acta Neurologica Taiwanica; and has received research support from the Ministry of Science and Technology. Dr. Pei-Chien Tsai, Dr. Yuh-Cherng Guo, Dr. Cheng-Tsung Hsiao, Dr. Guan-Ting Liu, and Dr. Yi-Chu Liao report no disclosures. Dr. Bing-wen Soong has served on the scientific 
advisory board of Taiwan Ataxia Advisory Group; has received travel/speaker honoraria from Steminent Biotherapeutics Inc.; has served on the editorial boards of Neurogenetics, Cerebellum and Ataxia, the Journal of Neurology and Psychology, the American Journal of Neurodegeneration, the International Journal of Medicine, the International Journal of Brain Science, the World Journal of Clinical Case Conference, the World Journal of Neurology, and the Scientific World Journal; and has received research support from the National Science Council (Taiwan) and the Taiwan Ataxia Advisory Group. Go to Neurology.org/ng for full disclosure forms.

Received August 4, 2015. Accepted in final form March 1, 2016.

\section{REFERENCES}

1. Kobayashi H, Abe K, Matsuura T, et al. Expansion of intronic GGCCTG hexanucleotide repeat in NOP56 causes SCA36, a type of spinocerebellar ataxia accompanied by motor neuron involvement. Am J Hum Genet 2011;89:121-130.

2. Garcia-Murias M, Quintans B, Arias M, et al. "Costa da Morte" ataxia is spinocerebellar ataxia 36: clinical and genetic characterization. Brain 2012;135:1423-1435.

3. Todd PK, Paulson HL. RNA-mediated neurodegeneration in repeat expansion disorders. Ann Neurol 2010;67: 291-300.

4. Ikeda Y, Ohta Y, Kobayashi H, et al. Clinical features of SCA36: a novel spinocerebellar ataxia with motor neuron involvement (Asidan). Neurology 2012;79:333-341.

5. Obayashi M, Stevanin G, Synofzik M, et al. Spinocerebellar ataxia type 36 exists in diverse populations and can be caused by a short hexanucleotide GGCCTG repeat expansion. J Neurol Neurosurg Psychiatry 2015;86:986-995.

6. Sugihara K, Maruyama H, Morino H, et al. The clinical characteristics of spinocerebellar ataxia 36: a study of 2121 Japanese ataxia patients. Mov Disord 2012;27: 1158-1163.

7. Guo YC, Lin JJ, Liao YC, Tsai PC, Lee YC, Soong BW. Spinocerebellar ataxia 35: novel mutations in TGM6 with clinical and genetic characterization. Neurology 2014;83: 1554-1561.

8. Wang JL, Yang X, Xia K, et al. TGM6 identified as a novel causative gene of spinocerebellar ataxias using exome sequencing. Brain 2010;133:3510-3518.

9. Bakalkin G, Watanabe H, Jezierska J, et al. Prodynorphin mutations cause the neurodegenerative disorder spinocerebellar ataxia type 23. Am J Hum Genet 2010;87: 593-603.

10. Geschwind DH, Perlman S, Figueroa KP, Karrim J, Baloh RW, Pulst SM. Spinocerebellar ataxia type 6 . Frequency of the mutation and genotype-phenotype correlations. Neurology 1997;49:1247-1251.

11. Ikeuchi T, Takano H, Koide R, et al. Spinocerebellar ataxia type 6: CAG repeat expansion in alpha1A voltage-dependent calcium channel gene and clinical variations in Japanese population. Ann Neurol 1997; 42:879-884.

12. Harding AE. Clinical features and classification of inherited ataxias. Adv Neurol 1993;61:1-14.

13. Brooks BR, Miller RG, Swash M, Munsat TL; World Federation of Neurology Research Group on Motor Neuron Diseases. El Escorial revisited: revised criteria for the diagnosis of amyotrophic lateral sclerosis. Amyotroph Lateral Scler Other Motor Neuron Disord 2000;1: 293-299.

14. Schmitz-Hubsch T, du Montcel ST, Baliko L, et al. Scale for the assessment and rating of ataxia: development of a new clinical scale. Neurology 2006; 66:1717-1720.

15. Lee YC, Liao YC, Wang PS, Lee IH, Lin KP, Soong BW. Comparison of cerebellar ataxias: a three-year prospective longitudinal assessment. Mov Disord 2011;26:20812087.

16. Lirng JF, Wang PS, Chen HC, et al. Differences between spinocerebellar ataxias and multiple system atrophycerebellar type on proton magnetic resonance spectroscopy. PLoS One 2012;7:e47925.

17. Wang PS, Chen HC, Wu HM, Lirng JF, Wu YT, Soong BW. Association between proton magnetic resonance spectroscopy measurements and CAG repeat number in patients with spinocerebellar ataxias 2, 3, or 6. PLoS One 2012;7:e47479.

18. Chia EM, Wang JJ, Rochtchina E, Cumming RR, Newall P, Mitchell P. Hearing impairment and healthrelated quality of life: the Blue Mountains Hearing Study. Ear Hear 2007;28:187-195.

19. Folstein MF, Folstein SE, McHugh PR. "Mini-mental state." A practical method for grading the cognitive state of patients for the clinician. J Psychiatr Res 1975; 12:189-198.

20. Nasreddine ZS, Phillips NA, Bedirian V, et al. The Montreal Cognitive Assessment, MoCA: a brief screening tool for mild cognitive impairment. J Am Geriatr Soc 2005;53: 695-699.

21. Dubois B, Slachevsky A, Litvan I, Pillon B. The FAB: a frontal assessment battery at bedside. Neurology 2000;55: $1621-1626$.

22. Zhang K, Sun F, Zhao H. HAPLORE: a program for haplotype reconstruction in general pedigrees without recombination. Bioinformatics 2005;21:90-103.

23. Neitzel H. A routine method for the establishment of permanent growing lymphoblastoid cell lines. Hum Genet 1986;73:320-326.

24. Ikeda Y, Ohta Y, Kurata T, Shiro Y, Takao Y, Abe K. Acoustic impairment is a distinguishable clinical feature of Asidan/SCA36. J Neurol Sci 2013;324:109-112.

25. Abe K, Ikeda Y, Kurata T, et al. Cognitive and affective impairments of a novel SCA/MND crossroad mutation Asidan. Eur J Neurol 2012;19:1070-1078.

26. Rohrer JD, Isaacs AM, Mizielinska S, et al. C9orf72 expansions in frontotemporal dementia and amyotrophic lateral sclerosis. Lancet Neurol 2015;14:291-301.

27. Cleary JD, Ranum LP. Repeat-associated non-ATG (RAN) translation in neurological disease. Hum Mol Genet 2013;22:R45-R51.

28. Simone R, Fratta P, Neidle S, Parkinson GN, Isaacs AM. G-quadruplexes: Emerging roles in neurodegenerative diseases and the non-coding transcriptome. FEBS Lett 2015; 589:1653-1668.

29. New nomenclature and DNA testing guidelines for myotonic dystrophy type 1 (DM1). The International Myotonic Dystrophy Consortium (IDMC). Neurology 2000;54:1218-1221.

30. Savic Pavicevic D, Miladinovic J, Brkusanin M, et al. Molecular genetics and genetic testing in myotonic dystrophy type 1. Biomed Res Int 2013;2013:391821.

31. Matsuura T, Yamagata T, Burgess DL, et al. Large expansion of the ATTCT pentanucleotide repeat in spinocerebellar ataxia type 10. Nat Genet 2000;26:191-194.

32. Teive HA, Munhoz RP, Arruda WO, Raskin S, Werneck LC, Ashizawa T. Spinocerebellar ataxia type 
10-A review. Parkinsonism Relat Disord 2011;17: 655-661.

33. Sakai H, Yoshida K, Shimizu Y, Morita H, Ikeda S, Matsumoto N. Analysis of an insertion mutation in a cohort of 94 patients with spinocerebellar ataxia type 31 from Nagano, Japan. Neurogenetics 2010;11: 409-415.
34. Sato N, Amino T, Kobayashi K, et al. Spinocerebellar ataxia type 31 is associated with "inserted" pentanucleotide repeats containing (TGGAA)n. Am J Hum Genet 2009;85:544-557.

35. Woollacott IO, Mead S. The C9ORF72 expansion mutation: gene structure, phenotypic and diagnostic issues. Acta Neuropathol 2014;127:319-332. 


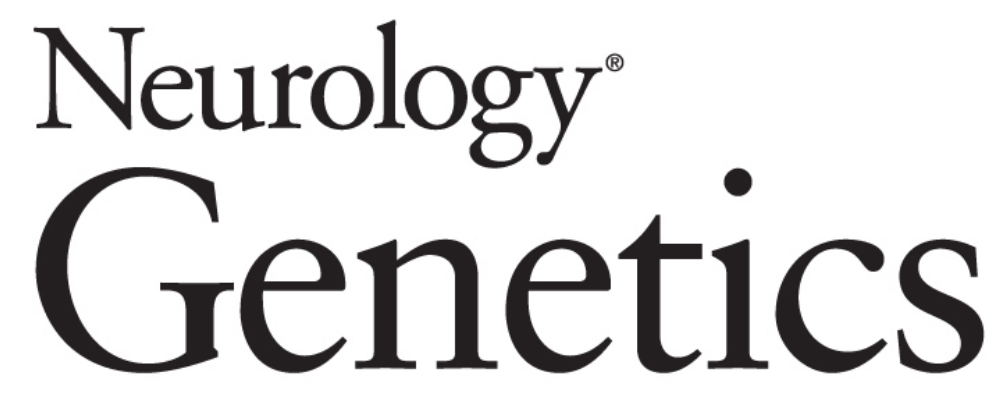

\author{
Spinocerebellar ataxia type 36 in the Han Chinese \\ Yi-Chung Lee, Pei-Chien Tsai, Yuh-Cherng Guo, et al. \\ Neurol Genet 2016;2; \\ DOI 10.1212/NXG.0000000000000068
}

This information is current as of April 12, 2016

\section{Updated Information \& Services \\ Supplementary Material}

References

Citations

Subspecialty Collections

Permissions \& Licensing

Reprints including high resolution figures, can be found at: http://ng.neurology.org/content/2/3/e68.full.html

Supplementary material can be found at: http://ng.neurology.org/content/supp1/2016/04/12/2.3.e68.DC1

This article cites 35 articles, 1 of which you can access for free at: http://ng.neurology.org/content/2/3/e68.full.html\#\#ref-list-1

This article has been cited by 1 HighWire-hosted articles: http://ng.neurology.org/content/2/3/e68.full.html\#\#otherarticles

This article, along with others on similar topics, appears in the following collection(s):

Amyotrophic lateral sclerosis

http://ng.neurology.org//cgi/collection/amyotrophic_lateral_sclerosis_ Spinocerebellar ataxia

http://ng.neurology.org//cgi/collection/spinocerebellar_ataxia

Information about reproducing this article in parts (figures,tables) or in its entirety can be found online at:

http://ng.neurology.org/misc/about.xhtml\#permissions

Information about ordering reprints can be found online: http://ng.neurology.org/misc/addir.xhtml\#reprintsus

Neurol Genet is an official journal of the American Academy of Neurology. Published since April 2015, it is an open-access, online-only, continuous publication journal. Copyright $(2016$ American Academy of Neurology. All rights reserved. Online ISSN: 2376-7839.

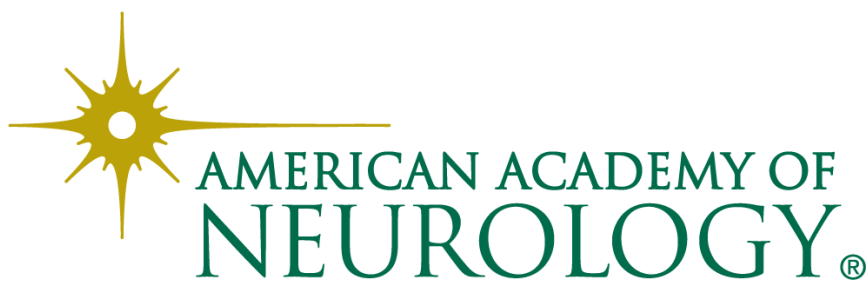

